\title{
P05.49. Development of a model for the conduct of randomized clinical trials of hypnotic intervention
}

\author{
C Kendrick*, G Elkins \\ From International Research Congress on Integrative Medicine and Health 2012 \\ Portland, Oregon, USA. 15-18 May 2012
}

\section{Purpose}

Research on the efficacy of hypnosis has been limited due to the lack of a sham hypnosis (placebo) for comparison to use as a control in randomized clinical trials. Researchers have used a variety of controls ranging from wait-lists to structured attention, resulting in a lack of blinding of participants and inconsistency. A sham hypnosis methodology would provide a means to compare study results and make aggregate statements regarding hypnosis' efficacy beyond placebo effects.

The purpose of this study involved two primary aims: 1) to evaluate whether white noise can be considered an "inert" procedure; and 2) to evaluate the feasibility of a model of sham hypnosis that uses white noise as a potential form of "hypnosis" when presented within the hypnotic context.

\section{Methods}

Seventy-five undergraduate students were randomized to one of three groups: hypnosis; sham (white noise presented in the context of hypnosis); or control (white noise in the absence of hypnotic context). Measures of interest involved participants' ratings of: (1) therapist's professionalism; (2) the consistency of the environment with hypnosis; (3) subjects' perception that they received hypnosis; (4) subjects' evaluation of the procedure as pleasant, relaxing, and beneficial; (5) participants' perception of the procedure as acceptable, ethical, and effective; and (6) shifts in relaxation resulting from each procedure.

\section{Results}

In each of the variables of interest, subjects who received sham hypnosis and those who received a

Baylor University, Department of Psychology and Neuroscience, Waco, USA hypnotic induction demonstrated significant differences from those assigned to the white noise control, with effect sizes ranging from .165 to .852 . However, there were no significant differences between participants' ratings of the sham and hypnosis procedure in any of these domains.

\section{Conclusion}

Results support the feasibility of using white noise as an inert procedure that, given the proper environmental context, can serve as a credible sham hypnosis.

Published: 12 June 2012

doi:10.1186/1472-6882-12-S1-P409

Cite this article as: Kendrick and Elkins: P05.49. Development of a model for the conduct of randomized clinical trials of hypnotic intervention. BMC Complementary and Alternative

Medicine 2012 12(Suppl 1):P409.

Submit your next manuscript to BioMed Central and take full advantage of:

- Convenient online submission

- Thorough peer review

- No space constraints or color figure charges

- Immediate publication on acceptance

- Inclusion in PubMed, CAS, Scopus and Google Scholar

- Research which is freely available for redistribution

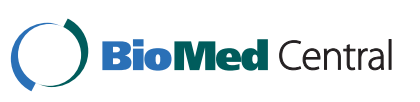

(c) 2012 Kendrick and Elkins; licensee BioMed Central Ltd. This is an Open Access article distributed under the terms of the Creative Commons Attribution License (http://creativecommons.org/licenses/by/2.0), which permits unrestricted use, distribution, and reproduction in any medium, provided the original work is properly cited. 